\title{
Dihydroergotamine, Ergotamine, Methysergide and Sumatriptan - Basic Science in Relation to Migraine Treatment
}

\author{
Carl Dahlöf, MD, PhD; Antoinette Maassen Van Den Brink, PhD
}

The 5-hydroxytryptamine (5-HT) receptor family mediates the effects of several drugs highly effective in migraine primarily by activating $5-\mathrm{HT}_{1 \mathrm{~B}}, 5-\mathrm{HT}_{1 \mathrm{D}}$, and $5-\mathrm{HT}_{1 \mathrm{~F}}$ receptors. Ergotamine, dihydroergotamine, and methysergide, as well as the "triptan" sumatriptan, are all agonists for these receptors. The receptor profile and degree of selectivity of these four drugs differ, which is reflected by their side effects that limit their use in the acute and prophylactic treatment of migraine. The acute antimigraine efficacy of these remedies is very much dependent on the formulation used where, in general, parenteral formulations are more effective in reliving the symptoms of a migraine attack.

Key words: migraine, headache, ergotamine, sumatriptan

Serotonin (5-hydroxytryptamine; 5-HT) is monoamine that has been found to play a fundamental role in the regulation of physiologic and pathophysiologic processes. ${ }^{1}$ The serotonin receptor family is currently grouped into 7 subfamilies $\left(5-\mathrm{HT}_{1}\right.$ to $5-\mathrm{HT}_{7}$ ) and 14 receptor subtypes ${ }^{2}$ that have different anatomic locations. All the receptors, with the exception of the $5-\mathrm{HT}_{3}$ receptor, belong to the super family of 7 transmembrane domain G-protein-linked receptors. ${ }^{3}$ The 5-HT receptor family mediates the effects of several drugs highly effective in migraine primarily by activating $5-\mathrm{HT}_{1 \mathrm{~B}}, 5-\mathrm{HT}_{1 \mathrm{D}}$, and $5-\mathrm{HT}_{1 \mathrm{~F}}$ receptors. ${ }^{4-7} \mathrm{The}$ ergot alkaloids, also referred to as "ergots," ergotamine, dihydroergotamine (DHE), and methysergide, as well as the "triptan" sumatriptan, are all agonists for these receptors. ${ }^{8,9}$ Ergotamine and DHE were the first specific acute antimigraine drugs for several decades until the advent of the triptans ${ }^{10}$ that are also used in the acute treatment of migraine. In contrast, methysergide is used as a prophylactic drug to prevent migraine attacks.

Ergotamine and DHE were originally developed as sympatholytics, but it was later concluded that their therapeutic efficacy was probably mediated by vasoconstriction of cranial blood vessels (for review, see Müller-Schweinitzer ${ }^{11}$ ). As expected from this pharmacologic profile, their most important pharmacologic effect is arterial constriction. ${ }^{11,12}$ Indeed, at therapeutic

From the Gothenburg Migraine Clinic AB, Gothenburg, Sweden (C. Dahlöf); Erasmus University Medical Centre, Rotterdam, The Netherlands (A. Maassen Van Den Brink).

Address all correspondence to C.G.H. Dahlöf, Gothenburg Migraine Clinic AB, Hovås Lingonstig 4, SE-436 55 Hovås, Sweden.

Accepted for publication September 30, 2011.

Headache

(C) 2012 American Headache Society concentrations, ergotamine and DHE induce a potent vasoconstriction in the external carotid (extracranial) vascular bed of anesthetized dogs mainly by activation of $\alpha$-adrenoceptors and 5-HT (mainly 5-HT ${ }_{1 \mathrm{~B}}$ ) receptors. ${ }^{13,14}$ Whereas both ergotamine and DHE constrict the cranial vascular bed, there is a difference in their capacity to constrict peripheral blood vessels. Ergotamine induces contraction of peripheral arteries, including the pulmonary, ${ }^{15}$ cerebral, ${ }^{11}$ temporal, ${ }^{16}$ and coronary ${ }^{17}$ arteries. In contrast, DHE is a more potent constrictor of venous capacitance vessels than of arteries. ${ }^{18}$ In humans, blood pressure is transiently increased for about 3 hours after parenteral therapeutic doses of ergotamine and DHE, ${ }^{19,20}$ which is likely caused by an increased peripheral resistance. ${ }^{21}$ In contrast, a much longer lasting constrictor effect on peripheral arteries (ergotamine) or veins (DHE) is induced. This is most likely caused by a slow diffusion from the receptor biophase; ${ }^{22}$ the effects last much longer than expected from the plasma concentrations. ${ }^{17,23,24}$ Thus, overall, based on in vitro, in vivo animal data and human clinical research, both ergotamine and DHE have the propensity to induce potent and long-lasting cardiovascular side effects, although the side effect profile of DHE is more favorable compared with that of ergotamine. ${ }^{25,26}$

Besides a vascular mode of action, which was originally believed to be the exclusive mechanism the antimigraine efficacy of ergot alkaloids, the neuronal properties of these compounds most probably also contribute to their clinical effects. The neuronal activity is probably mediated via the agonist activity at $5-\mathrm{HT}_{1 \mathrm{~B}}, 5-\mathrm{HT}_{1 \mathrm{D}}$, and $5-\mathrm{HT}_{1 \mathrm{~F}}$ receptors on trigeminal nerve terminals resulting in the inhibition of the neuronal release of vasoactive peptides and preventing vasodilatation in migraine. ${ }^{27}$

Methysergide does also have antagonistic properties on $5-\mathrm{HT}_{2}$ receptors, which were originally considered to underlie its therapeutic efficacy in migraine. However, given the fact that other potent $5-\mathrm{HT}_{2}$ receptor antagonists, such as mianserin, sergolexole, and ketanserin, are ineffective in the treatment of migraine, it is highly improbable that $5-\mathrm{HT}_{2}$ receptor antagonism plays a major role in migraine prophylaxis. ${ }^{28}$

In contrast with the ergot alkaloids, sumatriptan does not display affinity for the dopamine and noradrenaline receptors, and is thus pharmacologically more selective. ${ }^{29}$ In lower therapeutically relevant concentrations, ergotamine and DHE act as agonists at $\alpha$-adrenoceptors, 5 -HT (particularly $5-\mathrm{HT}_{1 \mathrm{~B} / 1 \mathrm{D}}$ ), and dopamine $\mathrm{D}_{2}$ receptors. ${ }^{8}$ Moreover, DHE and sumatriptan do

Conflict of Interest: None. 
not cause the dubious side effect of fibrotic changes, like retroperitoneal fibrosis, which is mediated by $5-\mathrm{HT}_{2 \mathrm{~B}}$ receptors and has been reported for both methysergide and ergotamine. ${ }^{30,31}$ Furthermore, the pharmacokinetic properties of each of these drugs can be markedly affected by its formulation and thus, the route of administration. ${ }^{32}$ Although oral formulations are the most popular among patients, they are not the most appropriate route of administration for drug delivery during the migraine attack. Because of gastrointestinal dysmotility, the intestinal absorption of any triptan given orally may be impaired, and treatment effects become inconsistent. ${ }^{33}$ Therefore, more consideration should be given to prescribing triptans in a non-oral formulation (injection, nasal spray, or suppository). Parenteral administration of a triptan is more likely to provide relief of symptoms, even when it is used later in the course of the migraine attack. $^{34}$

Migraine headache is a complex of symptoms that present clinically as discrete episodes of severe headache with associated features such as phonophobia, photophobia, nausea, and emesis. Migraine can be broadly characterized as headache pain with associated disturbances in sensory sensitivity. ${ }^{35}$ The specific cause of migraine headache is still unknown, although a number of recently discovered genetic factors seem to be important in some patients. ${ }^{36}$ These abnormalities involve neuronal ion channels that could regulate central nervous system (CNS) excitability in response to migraine trigger factors. ${ }^{35,36}$ The trigeminal sensory nerves arise from neurons in the trigeminal ganglia that have pseudo-unipolar morphology. Nerve fibers arising from the trigeminal neurons innervate cranial blood vessels in the periphery. ${ }^{37}$ Trigeminal fibers relevant to nociception project centrally behind the blood brain barrier by way of the descending spinal trigeminal tract and terminate in the spinal trigeminal nucleus in the medulla. ${ }^{38,39}$ Because of somatotopic organization, sensory fibers that innervate the dura mater terminate within the most caudal region of the nucleus (ie, trigeminal nucleus caudalis). Thus, trigeminal sensory neurons provide a pathway to convey nociceptive information from blood vessels in the meninges into the CNS. This system is referred to as the trigeminovascular system. ${ }^{40}$ When activated, perivascular sensory nerves release vasoactive neuropeptides (eg, substance $\mathrm{P}$, calcitonin gene-related peptide, neurokinin A). ${ }^{40-44}$ Peptide release from these fibers can result in the transmission of nociceptive impulses to second-order sensory neurons in the trigeminal nucleus caudalis that then relay this information to higher CNS centers. ${ }^{45}$ Central pain transmission activates CNS autonomic nuclei in the brainstem and other ascending nervous pathways, and this may, in turn, contribute to the production of the symptoms that are associated with migraine, namely nausea, emesis, phonophobia, and photophobia. ${ }^{46}$

5- $\mathrm{HT}_{1}$ agonists have 4 potential mechanisms of action: $:^{4,5,47-50}$
1. Stimulation of the $5-\mathrm{HT}_{1 \mathrm{~B}}$ receptor on cranial vascular smooth muscle is hypothesized to increase the tonus of the vessel wall, which counteracts the pulse synchronic activation of stretch receptors that may be responsible for throbbing headache.

2. Stimulation of the $5-\mathrm{HT}_{1 \mathrm{D}}$ receptors on trigeminal nerve terminals innervating the meningeal blood vessels to block the release of neuropeptides that are theorized to induce pain/inflammation.

3. Stimulation of central $5-\mathrm{HT}_{1 \mathrm{~B} / 1 \mathrm{D} / 1 \mathrm{~F}}$ receptors in the trigeminal nucleus caudalis to impair the transmission of afferent signaling from the first-order to the second-order trigeminal sensory neurons and preventing wind-up (temporal summation) in the trigeminal sensory processing and longlasting central sensitization (pain hypersensitivity).

4. Stimulation of the 5-HT $\mathrm{H}_{1 \mathrm{~B} / \mathrm{1D}}$ receptors in the ventroposteromedial (VPM) thalamus to inhibit the process of nociceptive input from to the second-order to the third-order trigeminal sensory neurons in VPM thalamus.

Which mechanism is the most important is as yet unclear. These actions inhibit the effects of activated nociceptive trigeminal afferents and, in this way, control the symptoms induced during an acute attacks of migraine.

The main objective with this review is to enlighten the pharmacodynamic and pharmacokinetic properties of ergotamine, DHE, sumatriptan, and methysergide in relation to existing formulations and their use in acute and prophylactic treatment of migraine.

\section{Dihydroergotamine-Pharmacodynamic and Pharmacokinetic Properties}

DHE (Fig. 1) displays affinity for a wide variety of receptors including those for 5-HT (serotonin), dopamine, and noradrenaline (see Table 1 and Müller-Schweinitzer ${ }^{11}$ ). The absolute bioavailability of intramuscular (i.m.) DHE is $100 \%$. The absolute bioavailability of DHE following intranasal (i.n.) administration,

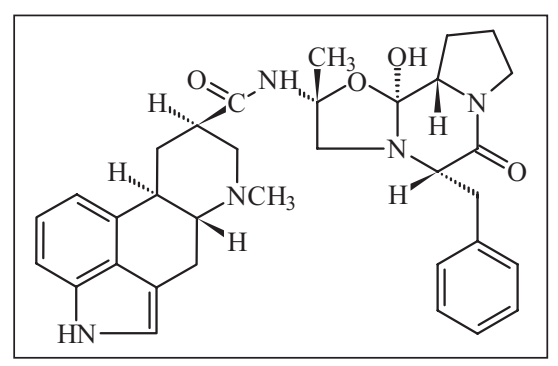

Fig 1.-Dihydroergotamine. Chemical structure: The chemical name of dihydroergotamine is ergotaman-3',6',18-trione,9,10-dihydro-12'hydroxy-2'-methyl-5'-(phenylmethyl)-(5' $\alpha)$-monomethanesulfonate. Its molecular weight is 583.68, and its empirical formula is $\mathrm{C}_{33} \mathrm{H}_{37} \mathrm{~N}_{5} \mathrm{O}_{5} \cdot \mathrm{CH}_{4} \mathrm{O}_{3} \mathrm{~S}$ (mesylate salt). 
which avoids first-pass hepatic metabolism, is approximately $40 \%$. Peak plasma levels occur approximately 1-2 minutes after i.v. administration, 24 minutes after i.m. administration and 30-60 minutes after i.n. administration. Bioavailability after oral administration is less than $1 \%$ (for review, see Saper and Silberstein $\left.^{25}\right)$. DHE is rapidly and extensively metabolized in the liver. Only $6-7 \%$ of an i.m. dose is excreted in the urine. The major route of elimination is the feces following biliary excretion of unchanged drug and metabolites. DHE has many metabolites; only those that retain the essential ring structures of the ergot alkaloids (the ergoline ring and the peptide side chain) are active. The major metabolite is 8 '-OH DHE that is present at a concentration 5 to 7 times greater than that of DHE. The pharmacologic effects of the active metabolites are qualitatively similar to those of the parent compound. DHE is eliminated in a biphasic manner, with mean half-lives of approximately $0.7-1$ and $10-13$ hours.

Because of slow diffusion from the receptor biophase, the effects of DHE, as well as for ergotamine, last far longer than can be expected from plasma concentrations. For this reason, the pharmacokinetic data of ergotamine and DHE available cannot be used to predict the biologic response.

\begin{tabular}{|c|c|c|c|c|}
\hline Receptor & DHE & Ergotamine & Sumatriptan & Methysergide \\
\hline $5-\mathrm{HT}_{1 \mathrm{~A}}$ & +++ & +++ & ++ & $++^{*}$ \\
\hline $5-\mathrm{HT}_{1 \mathrm{~B}}$ & +++ & +++ & +++ & $++^{*}$ \\
\hline $5-\mathrm{HT}_{1 \mathrm{D}}$ & +++ & +++ & +++ & $++^{*}$ \\
\hline $5-\mathrm{HT}_{1 \mathrm{E}}$ & + & + & + & N.D. \\
\hline $5-\mathrm{HT}_{1 \mathrm{~F}}$ & + & + & ++ & N.D. \\
\hline $5-\mathrm{HT}_{2 \mathrm{~A}}$ & ++ & N.D. & 0 & $+^{*}$ \\
\hline $5-\mathrm{HT}_{2 \mathrm{C}}$ & ++ & N.D. & 0 & N.D. \\
\hline $5-\mathrm{HT}_{3}$ & 0 & 0 & 0 & N.D. \\
\hline $5-\mathrm{HT}_{4}$ & + & + & 0 & N.D. \\
\hline$\alpha_{1 a}$ & ++ & ++ & 0 & $0^{* *}$ \\
\hline$\alpha_{1 b}$ & ++ & ++ & 0 & N.D. \\
\hline$\alpha_{2 a}$ & +++ & N.D. & 0 & $0^{* *}$ \\
\hline$\alpha_{2 b}$ & +++ & N.D. & 0 & N.D. \\
\hline$\alpha_{2 c}$ & +++ & N.D. & 0 & N.D. \\
\hline$\beta_{1}$ & 0 & N.D. & 0 & N.D. \\
\hline$\beta_{2}$ & 0 & N.D. & 0 & N.D. \\
\hline$\beta_{3}$ & + & N.D. & 0 & N.D. \\
\hline $\mathrm{D}_{2}$ & +++ & +++ & 0 & $+* *$ \\
\hline $\mathrm{D}_{3}$ & ++ & +++ & 0 & N.D. \\
\hline $\mathrm{D}_{4}$ & ++ & +++ & 0 & N.D. \\
\hline
\end{tabular}

Values for methysergide refer to ${ }^{*} K_{\mathrm{D}}$ values ${ }^{59}$ and ${ }^{* *} \mathrm{~K}_{\mathrm{i}}$ values, ${ }^{60}$ respectively. Values for N.D. $=$ not determined.,,++++++ and 0 indicate IC50 affinities $(\mathrm{nM})<5 \mathrm{nM},>5$ to $<50 \mathrm{nM}$. $>50$ to $<1500 \mathrm{nM}$, and $>1500 \mathrm{nM}$, respectively.
An interaction with erythromycin may dramatically increase the oral bioavailability of ergotamine and DHE. ${ }^{53}$ Because the same cytochrome P450 enzyme CYP3A4 metabolizes a number of other drugs, including bromocriptine, dexamethasone, ethinyloestradiol, ketoconazole, nifedipine, omeprazole, and verapamil, this interaction may extend to these drugs as well. ${ }^{54}$

\section{Formulations}

DHE is available as subcutaneous (1 mg), i.m. (1 mg), intravenous (i.v.) $(1 \mathrm{mg})$, and intranasal $(2 \mathrm{mg})$ formulations. Recently, clinical trials have been performed with MAP0004, an orally inhaled formulation of DHE, which reaches efficacy against migraine with a lower $\mathrm{C}_{\max }$ than observed after i.v. administration. ${ }^{55}$

\section{Adverse events}

DHE may increase the risk of dangerously decreased blood flow to the brain, heart, or extremities. In rare but severe cases, gangrene or other serious problems can result.

\section{Contraindications}

Peripheral vascular disease or poor circulation, arteriosclerosis, hypertension, angina (history of heart attack, silent ischemia), liver disease, kidney disease, and serious infections.

\section{Pregnancy/nursing}

DHE can be very harmful if used during pregnancy. DHE can induce uterine contractions, and it can restrict blood flow to the fetus. Patients should not use DHE if they are pregnant or could become pregnant during treatment. In a Swedish registry, however, there was no increased risk for congenital malformations after maternal use of DHE or ergotamine. ${ }^{61}$ DHE passes into breast milk and may be harmful to a nursing infant. DHE may also decrease milk production. Thus, patients should not use DHE during lactation.

\section{Ergotamine-Pharmacodynamic and Pharmacokinetic Properties}

Similar to DHE, ergotamine displays affinity for a wide variety of receptors including those for 5-HT (serotonin), dopamine, and noradrenaline (see Table 1 and Müller-Schweinitzer ${ }^{11}$ ). Oral absorption of ergotamine (Fig. 2) is $60-70 \%$, and the concurrent administration of caffeine improves both the rate and extent of absorption. However, because of high first-pass metabolism, ergotamine has a very low oral and rectal bioavailability. If compared with its i.v. bioavailability $(100 \%)$, oral bioavailability of ergotamine is $<1 \%$, rectal bioavailability of ergotamine is $1-3 \%$, and i.m. bioavailability of ergotamine is $47 \% .^{56,57}$ Ergotamine is metabolized in the liver by largely undefined pathways, and $90 \%$ of the metabolites are excreted in the low oral bioavailability (less than $1 \%$ ) because of incomplete drug passage across the gastrointestinal mucosa and a high first-pass metabolism..$^{57,58}$ The absolute bioavailability of i.m. ergotamine is $100 \%$. 


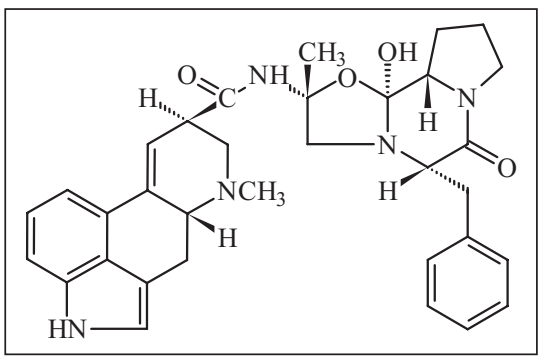

Fig 2.-Ergotamine. Chemical structure: The chemical name of ergotamine is $(6 \mathrm{aR}, 9 \mathrm{R})-\mathrm{N}-((2 \mathrm{R}, 5 \mathrm{~S}, 10 \mathrm{aS}, 10 \mathrm{bS})-$ 5-benzyl-10bhydroxy-2-methyl- 3,6-dioxooctahydro-2H-oxazolo[3,2-a] pyrrolo [2,1-c]pyrazin-2-yl) -7-methyl-4,6,6a,7,8,9-hexahydroindolo[4,3-fg] quinoline-9-carboxamide. Molecular weight is 581.66, and its empirical formula is $\mathrm{C}_{33} \mathrm{H}_{35} \mathrm{~N}_{5} \mathrm{O}_{5}$.

\section{Formulations}

Ergotamine is available in combination with caffeine as a conventional tablet form $(0.5 \mathrm{mg}$ and $50 \mathrm{mg}$, respectively) and in some countries it is also available in a suppository form $(1 \mathrm{mg}$ and $100 \mathrm{mg}$, respectively).

\section{Adverse events}

Ergotamine may increase the risk of dangerously decreased blood flow to the brain, heart, or extremities. In rare but severe cases, gangrene or other serious problems can result. Commonly reported adverse events are nausea; vomiting; weakness; or coldness, numbness, or pain in the hands, feet, arms, or legs.

\section{Contraindications}

Peripheral vascular disease or poor circulation, arteriosclerosis, hypertension, angina (history of heart attack, silent ischemia), liver disease, kidney disease, and serious infections.

\section{Pregnancy/nursing}

The use of ergotamine during pregnancy is associated with a shorter mean gestational age and smaller mean birth weight, in addition to a higher rate of low birthweight newborns and preterm births. ${ }^{59}$ These associations might be explained by the uterotonic effects of ergotamine, as well as its vasoconstrictive effect on the placenta and the umbilical cord. Ergotamine passes into breast milk and may be harmful to a nursing infant. Thus, ergotamine should not be used during pregnancy or lactation (Fig. 3).

\section{Sumatriptan-Pharmacodynamic and Pharmacokinetic Properties}

Sumatriptan (Fig. 3) is a potent, selective $5-\mathrm{HT}_{1 \mathrm{~B} / 1 \mathrm{D} / 1 \mathrm{~F}}$ receptor agonist, having high affinity for human $5-\mathrm{HT}_{1 \mathrm{~B}}$ and $5-\mathrm{HT}_{1 \mathrm{D}}$ receptors, with a slightly lower affinity at $5-\mathrm{HT}_{1 \mathrm{~F}}$ receptors (see Table 1). ${ }^{47,60}$ It displays only a weak affinity at $5-\mathrm{HT}_{1 \mathrm{~A}}$ and 5- $\mathrm{HT}_{1 \mathrm{E}}$ receptors (Table 1) At clinically relevant doses, concentrations of sumatriptan achieved doses $\left(\mathrm{C}_{\max }\right.$ of $54-77 \mathrm{ng} / \mathrm{mL}$,

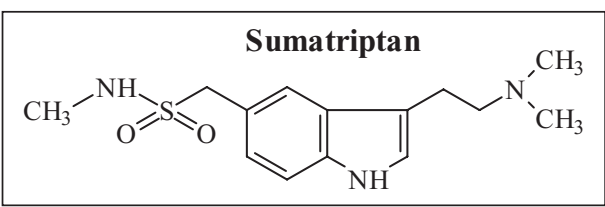

Fig 3.-Sumatriptan. Chemical structure: The chemical name of sumatriptan (Imigran ${ }^{\circledR}$ or Imitrex ${ }^{\mathrm{TM}}$ ) is 3-[2-(dimethylamino)ethyl]-Nmethyl-1H-indole-5-methanesulfonamide. Its empirical formula is $\mathrm{C}_{14} \mathrm{H}_{21} \mathrm{~N}_{3} \mathrm{O}_{2} \mathrm{~S}$, and its molecular weight is 295.4 . A white to off-white powder, sumatriptan is soluble in water and saline.

equivalent to $0.1-0.2 \mu \mathrm{M})$ are unlikely to be within the range required to activate $5-\mathrm{HT}_{1 \mathrm{~A}}$ or $5-\mathrm{HT}_{1 \mathrm{E}}$ receptors. Sumatriptan has no significant activity at other $5-\mathrm{HT}$ receptor types $\left(5-\mathrm{HT}_{2}\right.$ to $5-\mathrm{HT}_{7}$ ) or at a wide range of other non-5-HT receptors and ion channels (eg, adrenergic, dopaminergic, and histamine receptors) (see Table 1). Recent research has focused on the relative importance of 5- $\mathrm{HT}_{1 \mathrm{~B}}, 5-\mathrm{HT}_{1 \mathrm{D}}$, and $5-\mathrm{HT}_{1 \mathrm{~F}}$ receptors in mediating the clinical efficacy of sumatriptan. While a selective $5-\mathrm{HT}_{1 \mathrm{D}}$ receptor agonist was not effective in the treatment of migraine, ${ }^{62}$ the selective $5-\mathrm{HT}_{1 \mathrm{~F}}$ agonist lasmiditan is effective against migraine. ${ }^{63}$

Oral absorption of sumatriptan may be influenced by variable gastric emptying and small bowel transit. Multiple peaking occurs with a $t_{\max }$ of 2 hours. Oral bioavailability is low (14\%), and results from incomplete absorption and first-pass hepatic metabolism. ${ }^{47}$ Protein binding ranges from $14 \%$ to $21 \%$. Approximately $80 \%$ of a dose is hepatically metabolized. Metabolism produces an inactive metabolite and its glucuronide conjugate. Renal clearance is believed to be by tubular secretion as well as glomerular filtration. About $60 \%$ is excreted renally, primarily as the indole acetic acid metabolite with approximately $3 \%$ as unchanged drug. The remaining $40 \%$ is excreted in the feces. The mean terminal half-life is about 2 hours.

Other pharmacokinetic parameters for the various formulations of sumatriptan are summarized in Table 2. Of the longstanding sumatriptan formulations, the injection is most rapidly absorbed (time to maximum concentration $\left[\mathrm{t}_{\max }\right]=12$ minutes), followed by the nasal spray ( $\mathrm{t}_{\max }=1-1.5$ hours) and the suppositories ( $t_{\max } 1.5$ hours), followed by the conventional tablet $\left(t_{\max }=2\right.$ hours). Consistent with this pharmaceutic profile, the pharmacokinetic parameters measured 0-2 hours after dosing suggest slightly faster absorption, on average, of the fastdisintegrating/rapid-release tablet compared with the conventional sumatriptan tablet.

\section{Formulations}

Sumatriptan was initially introduced in an injectable formulation $(6 \mathrm{mg})$, which was soon followed in many countries by the introduction of a conventional tablet form (available in 25-mg, 50-mg, and 100-mg strengths depending on the country) and a 


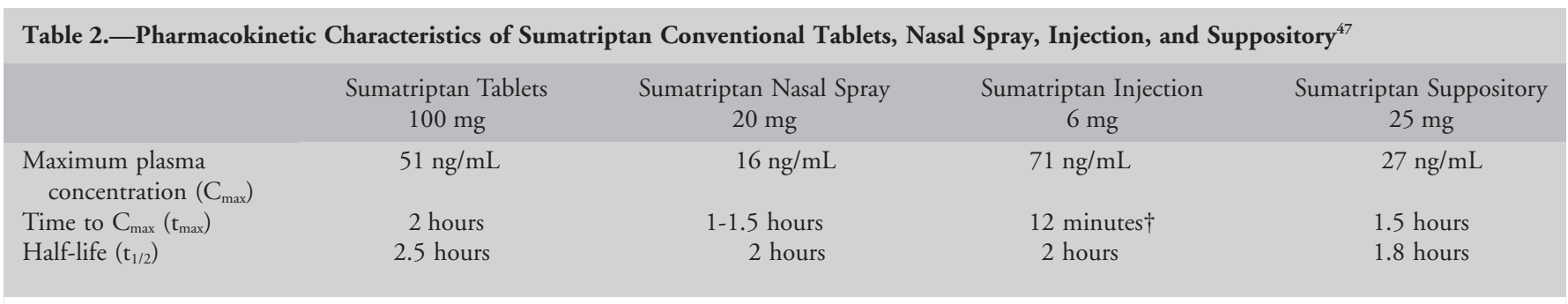

$\dagger$ After subcutaneous injection into the deltoid area of the arm.

nasal spray form (available in 5-mg, 10-mg, and 20-mg strengths depending on the country). In some countries, sumatriptan is also available in a suppository form $(25 \mathrm{mg})$. The latest sumatrip$\tan$ formulation, a fast-disintegrating/rapid-release oral tablet, has recently been introduced into clinical practice. ${ }^{64}$ The fastdisintegrating/rapid-release tablet was developed in response to the consistent findings that patients prefer tablet forms of migraine medication to other forms.

\section{Adverse events}

The most common adverse event with sumatriptan injection is burning or stinging at the injection site, which was reported in approximately $60 \%$ of patients in clinical trials. Patients may also experience warm/hot sensation, tightness, tingling, flushing, and feelings of heaviness or pressure in areas such as the face, limbs, and chest. ${ }^{47}$ These events have been designated "triptan sensations" because they appear to occur with all sumatriptan-like compounds developed to date. That these symptoms sometimes occur in the chest has prompted concern among some prescribers about the cardiovascular safety of triptans. Having undertaken a comprehensive review of the pharmacologic and clinical data on cardiovascular effects of triptans, a panel of experts convened in 2002 by the American Headache Society concluded that chest symptoms occurring during use of triptans are generally nonserious and are not explained by ischemia; the incidence of serious cardiovascular events with triptans appears to be low, and the cardiovascular risk-benefit profile of triptans favors their use in the absence of contraindications. ${ }^{66}$ This assumption is strongly supported by the results two published retrospective studies. ${ }^{67,68}$ In one of these studies, 13,664 of 63,575 (21.5\%) migraine patients were using a triptan. In the second of these studies, 50,383 of $130,411(38.6 \%)$ were using a triptan. The use of triptans was not associated with increased risk of any ischemic events, including myocardial infarction and stroke, or mortality.

The most common adverse event in clinical studies of sumatriptan conventional tablets was nausea, which is possibly attributed to the migraine rather than to sumatriptan. In several clinical studies, the adverse event profile of sumatriptan tablets did not differ from that of placebo. Triptan sensations occur less frequently with sumatriptan tablets than with the injection.
The most common adverse event in clinical trials of sumatriptan nasal spray was a disturbance of taste, usually described as bad, bitter, unpleasant, or unusual, and reported in about one fourth of patients receiving sumatriptan nasal spray $20 \mathrm{mg} .{ }^{47}$ Other than disturbance of taste, adverse events with sumatriptan nasal spray were reported at frequencies similar to those of placebo.

The tolerability profile of the suppository was similar to that of placebo in controlled clinical trials. Anorectal adverse events such as burning, itching, or irritation were reported in less than $1 \%$ of patients.

\section{Contraindications}

Myocardial infarction, ischemic heart disease, or experienced coronary vasospasm; for review, see Dodick et al. ${ }^{66}$ Peripheral vessel disease. Symptoms that indicate ischemic heart disease, moderate-to-severe hypertension, disturbed liver function. History of stroke or transient ischemic attack (TIA).

\section{Pregnancy/nursing}

There are no data to suggest teratogenicity for sumatriptan or any of the other triptans, ${ }^{61,65}$ although data on the other triptans are still limited; see, eg, Cassina et al. ${ }^{69}$

\section{Methysergide-Pharmacodynamic and Pharmacokinetic Properties}

Methysergide (Fig. 4) is a potent antagonist at the $5-\mathrm{HT}_{7}$ (and 5- $-\mathrm{HT}_{2}$ ) receptor and an agonist at 5- $\mathrm{HT}_{1 \mathrm{~B}}$, and, possibly, also $5-\mathrm{HT}_{1 \mathrm{D}}$ receptors (see Table 1). In vitro functional and radioligand studies confirm that methysergide acts on $5-\mathrm{HT}_{1 \mathrm{~B}}$ receptors. Thus, methysergide contracts canine, bovine, and human cerebral arteries, and the methysergide-induced contraction of dog isolated saphenous vein is antagonized by the nonselective $5-\mathrm{HT}_{1}$ and $5-\mathrm{HT}_{2}$ receptor antagonist methiothepin but not by the $5-\mathrm{HT}_{2}$ receptor antagonist ketanserin.

The pharmacology of the metabolite methylergometrine has been less investigated. However, it is a more potent vasoconstrictor than methysergide both in vivo and in vitro on, eg, canine saphenous vein, and human basilar and coronary arteries.

The mechanism of action of methysergide in migraine is not well understood. The efficacy of methysergide has been ascribed 


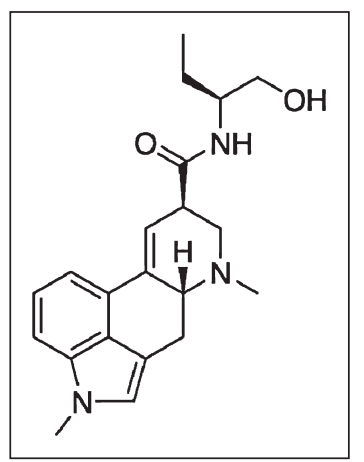

Fig 4.- Methysergide. Chemical structure: Methysergide maleate (Sansert ${ }^{\circledR)}$ is a partially synthetic compound structurally related to lysergic acid butanolamide, well known as methylergonovine in obstetrical practice as an oxytocic agent. Chemically, methysergide maleate is designated as ergoline-8-carboxamide, 9,10-didehydro- $\mathrm{N}$-[1(hydroxymethyl)propyl]-1,6-dimethyl- (8ß)- (Z)-2-butenedioate (1:1) (salt). It empirical formula is $\mathrm{C}_{21} \mathrm{H}_{27} \mathrm{~N}_{3} \mathrm{O}_{2} \cdot \mathrm{C}_{4} \mathrm{H}_{4} \mathrm{O}_{4}$, and its molecular weight is 353.46. Methylation in the number 1 position of the ring structure enormously enhances the antagonism to serotonin that is present to a much lesser degree in the partially methylated compound (methylergonovine maleate) as well as profoundly altering other pharmacologic properties.

to its $5-\mathrm{HT}_{2}$ receptor antagonist property. This is unlikely because potent $5-\mathrm{HT}_{2}$ receptor antagonists, such as mianserin, sergolexole, ketanserin, and ICI 169,369, seem to be without any prophylactic effect in migraine, and for cyproheptadine, the claimed efficacy has never been confirmed in controlled clinical trials. ${ }^{28}$ Therefore, it is highly improbable that $5-\mathrm{HT}_{2}$ receptor antagonism plays any role in migraine prophylaxis. Inhibition of peptide release from perivascular sensory nerve endings as well as neurogenic inflammation by methysergide, as demonstrated in the rat, has also been invoked as a mechanism of action in migraine. However, as argued elsewhere, there is considerable doubt whether inhihition of neurogenic inflammation in experimental animals is connected with antimigraine efficacy, as several such compounds were found clinically ineffective in migraine.

\section{Formulations}

Methysergide is only clinically available as a 1-mg tablet.

\section{Adverse events}

Retroperitoneal fibrosis, pleuropulmonary fibrosis, and fibrotic thickening of cardiac valves may occur in patients receiving longterm methysergide maleate therapy. ${ }^{30,31}$ Therefore, methysergide must be reserved for prophylaxis in patients whose vascular headaches are frequent and/or severe and uncontrollable, and who are under close medical supervision.

\section{Contraindications}

Contraindications to the use of methysergide include pregnancy, peripheral vascular disorders, severe arteriosclerosis, coronary artery disease, severe hypertension, thrombophlebitis or cellulitis of the legs, peptic ulcer disease, liver or renal function impairment, valvular heart disease, debilitation, or serious infection. As mentioned earlier, all patients receiving methysergide should remain under the supervision of the treating physician and be examined regularly for the development of the rare pulmonary/ cardiac or peritoneal fibrosis, or the development of vascular complications. ${ }^{31}$

\section{Pregnancy/nursing}

Methysergide should not be used during pregnancy.

\section{SUMMARY AND CONCLUSIONS}

Ergotamine, DHE, and methysergide have now been used in the treatment of migraine for many decades, and there is some evidence to support that their beneficial effects as antimigraine agents are likely to result from the activation of $5-\mathrm{HT}_{1 \mathrm{~B}}$ and $5-\mathrm{HT}_{1 \mathrm{D}}$ receptors. ${ }^{70}$ These findings led to the design and development of sumatriptan, which was the first of a novel class of drugs for the acute treatment of migraine, the so-called "triptans." Sumatriptan is a selective $5-\mathrm{HT}_{1 \mathrm{~B} / \mathrm{DD}}$ agonist, which lacks effects at the other ergot sensitive monoamine receptors that can mediate unwanted side effects like nausea, dysphoria, asthenia, and vascular effects. DHE offers, however, several benefits compared with ergotamine, including a lower incidence of nausea and vomiting, and in comparison with sumatriptan lower headache recurrence, and a lack of rebound headache. In particular, DHE does not appear to be associated with $5-\mathrm{HT}_{2 \mathrm{~B}}$-induced fibrosis that has been demonstrated for methysergide and ergotamine.

Ergotamine, DHE, and sumatriptan are available in different formulations of which the parenteral administration has been demonstrated to be associated with a faster onset of action and better efficacy. Appropriate use of their existing formulations may increase the intraindividual consistency of response and tolerability.

\section{References}

1. Villalón CM, Centurión D. Cardiovascular responses produced by 5-hydroxytriptamine: A pharmacological update on the receptors/ mechanisms involved and therapeutic implications. NaunynSchmiedebergs Arch Pharmacol. 2007;376:45-63.

2. Barnes NM, Andrade R, Bockaert J, et al. 5-Hydroxytryptamine receptors, introductory chapter. IUPHAR database (IUPHAR-DB). Available at: http://www.iuphar-db.org/DATABASE/Family IntroductionForward?familyId=1. Accessed March 5, 2012.

3. Peroutka SJ, Howell TA. The molecular evolution of G proteincoupled receptors: Focus on 5-hydroxytryptamine receptors. Neuropharmacology. 1994;33:319-324. 
4. Hargreaves RJ, Shepheard SL. Pathophysiology of migraine - new insights. Can J Neurol Sci. 1999;26(Suppl. 3):S12-S19.

5. Peroutka SJ, Havlik S, Oksenberg D. Wolff Award presentation 1993. Anti-migraine drug interactions with cloned human 5-hydroxytryptamine1 receptor subtypes. Headache. 1993;33:347350 .

6. Tfelt-Hansen P, De Vries P, Saxena PR. Triptans in migraine: A comparative review of pharmacology, pharmacokinetics and efficacy. Drugs. 2000;60:1259-1287.

7. van den Broek RW, Bhalla P, VanDenBrink AM, de Vries R, Sharma HS, Saxena PR. Characterization of sumatriptan-induced contractions in human isolated blood vessels using selective 5-HT(1B) and 5-HT(1D) receptor antagonists and in situ hybridization. Cephalalgia. 2002;22:83-93.

8. Silberstein SD, Hargreaves RJ. The history and pharmacology of ergotamine and dihydroergotamine. In: Diener HC, ed. Drug Treatment of Migraine and Other Frequent Headaches. Basel: Karger Press; 2000:52-65.

9. Tfelt-Hansen P, Saxena PR. 5-HT receptor antagonists in migraine prophylaxis. In: Diener HC, ed. Drug Treatment of Migraine and Other Frequent Headaches. Basel: Karger Press; 2000:279-287.

10. Silberstein SD, McCrory DC. Ergotamine and dihydroergotamine: History, pharmacology, and efficacy. Headache. 2003;43:144166.

11. Müller-Schweinitzer E. Ergot alkaloids in migraine: It the effect via 5-HT receptors? In: Olesen J, Saxena PR, eds. 5-Hydroxytryptamine Mechanisms in Primary Headaches. New York, NY: Raven; 1992: 297-304.

12. Müller-Schweinitzer E, Weidmann H. Basic pharmacological properties. In: Berde B, Schild HO, eds. Ergot Alkaloids and Related Compounds. Berlin, Heidelberg, New York, NY: Springer Verlag; 1978:87-232.

13. Valdivia LF, Centurión D, Arulmani U, Saxena PR, Villalón CM. 5- $\mathrm{HT}_{1 \mathrm{~B}}$ receptors, alpha $\mathrm{A}_{2} \mathrm{C}$ - and, to a lesser extent, alpha ${ }_{1}$ adrenoceptors mediate the external carotid vasoconstriction to ergotamine in vagosympathectomised dogs. Naunyn-Schmiedebergs Arch Pharmacol. 2004;370:46-53.

14. Villalón CM, De Vries P, Rabelo G, Centurión D, Sánchez-López A, Saxena PR. Canine external carotid vasoconstriction to methysergide, ergotamine and dihydroergotamine: Role of $5-\mathrm{HT}_{1 \mathrm{~B} / 1 \mathrm{D}}$ receptors and alpha 2 -adrenoceptors. Br J Pharmacol. 1999;126:585594.

15. Cortijo J, Marti-Cabrera M, Bernabeu E, et al. Characterization of 5-HT receptors on human pulmonary artery and vein: Functional and binding studies. Br J Pharmacol. 1997;122:1455-1463.

16. Ostergaard JR, Mikkelsen E, Voldby B. Effects of 5hydroxytryptamine and ergotamine on human superficial temporal artery. Cephalalgia. 1981;1:223-228.

17. MaassenVanDenBrink A, Reekers M, Bax WA, Ferrari MD, Saxena PR. Coronary side-effect potential of current and prospective antimigraine drugs. Circulation. 1998;98:25-30.

18. Silberstein SD. The pharmacology of ergotamine and dihydroergotamine. Headache. 1997;37(Suppl. 1):S15-S25.

19. Andersen AR, Tfelt-Hansen P, Lassen NA. The effect of ergotamine and dihydroergotamine on cerebral blood flow in man. Stroke. 1987;18:120-123.
20. Tfelt-Hansen P. The effect of ergotamine on the arterial system in man. Acta Pharmacol Toxicol (Copenh). 1986;59(Suppl. 3): 1-30.

21. Tfelt-Hansen P, Kanstrup IL, Christensen NJ, Winkler K. General and regional haemodynamic effects of intravenous ergotamine in man. Clin Sci. 1983;65:599-604.

22. Martin GR, Martin RS, Wood J. Long-acting 5-HT $1 \mathrm{D}$ receptor agonist effects of dihydroergotamine. In: Olesen J, Moskowitz MA, eds. Experimental Headache Models. Philadelphia, PA: LippincottRaven; 1995:163-167.

23. Tfelt-Hansen P, Paalzow L. Intramuscular ergotamine: Plasma levels and dynamic activity. Clin Pharmacol Ther. 1985;37:29-35.

24. De Hoon JN, Poppe KA, Thijssen HH, Struijker-Boudier HA, Van Bortel LM. Dihydroergotamine: Discrepancy between arterial, arteriolar and pharmacokinetic data. Br J Clin Pharmacol. 2001;52: 45-51.

25. Saper JR, Silberstein S. Pharmacology of dihydroergotamine and evidence for efficacy and safety in migraine. Headache. 2006; 46(Suppl. 4):S171-S181.

26. Silberstein SD, Young WB. Safety and efficacy of ergotamine tartrate and dihydroergotamine in the treatment of migraine and status migrainosus. Working Panel of the Headache and Facial Pain Section of the American Academy of Neurology. Neurology. 1995; 45:577-584.

27. Hoskin KL, Kaube H, Goadsby PJ. Central activation of the trigeminovascular pathway in the cat is inhibited by dihydroergotamine. A c-Fos and electrophysiological study. Brain. 1996;119:249256.

28. Saxena PR, Den Boer MO. Pharmacology of antimigraine drugs. J Neurol. 1991;238(Suppl. 1):S28-S35.

29. Feniuk W, Humphrey PPA, Perren MJ, Connor HE, Whalley ET. Rationale for the use of 5 - $\mathrm{HT}_{1}$-like agonists in the treatment of migraine. J Neurol. 1991;238(Suppl. 1):S57-S61.

30. Hofmann C, Penner U, Dorow R, et al. Lisuride, a dopamine receptor agonist with $5-\mathrm{HT}_{2 \mathrm{~B}}$ receptor antagonist properties: Absence of cardiac valvulopathy adverse drug reaction reports supports the concept of a crucial role for $5-\mathrm{HT}_{2 \mathrm{~B}}$ receptor agonism in cardiac valvular fibrosis. Clin Neuropharmacol. 2006;29:80-86.

31. Silberstein SD. Methysergide. Cephalalgia. 1998;18:421-435.

32. Dahlöf C. Integrating the triptans into clinical practice. Curr Opin Neurol. 2002;15:317-322.

33. Dahlöf CG. Non-oral formulations of triptans and their use in acute migraine. Curr Pain Headache Rep. 2005;9:206-212.

34. Linde M, Mellberg A, Dahlöf C. Subcutaneous sumatriptan provides symptomatic relief at any pain intensity or time during the migraine attack. Cephalalgia. 2006;26:113-121.

35. Dahlöf CGH, Diener H-C. Migraine - an endemic disease inside the blood-brain-barrier. Future Neurol. 2009;4:405-420.

36. de Vries B, Frants RR, Ferrari MD, van den Maagdenberg AM. Molecular genetics of migraine. Hum Genet. 2009;126:115-132.

37. Edvinsson L. Tracing neural connections to pain pathways with relevance to primary headaches. Cephalalgia. 2011;31:737-747.

38. Borsook D, Burstein R, Becerra L. Functional imaging of the human trigeminal system: Opportunities for new insights into pain processing in health and disease. J Neurobiol. 2004;61:107-125. 
39. Borsook D, Burstein R, Moulton E, Becerra L. Functional imaging of the trigeminal system: Applications to migraine pathophysiology. Headache. 2006;46(Suppl. 1):S32-S38.

40. Buzzi MG, Moskowitz MA. The trigemino-vascular system and migraine. Pathol Biol (Paris). 1992;40:313-317.

41. Goadsby PJ, Edvinsson L, Ekman R. Release of vasoactive peptides in the extracerebral circulation of humans and the cat during activation of the trigeminovascular system. Ann Neurol. 1988;23:193-196.

42. Zimmermann K, Reeh PW, Averbeck B. ATP can enhance the proton-induced CGRP release through P2Y receptors and secondary PGE(2) release in isolated rat dura mater. Pain. 2002;97:259-265.

43. Zimmermann K, Reeh PW, Averbeck B. S+ -flurbiprofen but not 5-HT1 agonists suppress basal and stimulated CGRP and PGE2 release from isolated rat dura mater. Pain. 2003;103:313-320.

44. Xiao Y, Richter JA, Hurley JH. Release of glutamate and CGRP from trigeminal ganglion neurons: Role of calcium channels and 5-HT1 receptor signaling. Mol Pain. 2008;4:12 Abstract.

45. Jenkins DW, Langmead CJ, Parsons AA, Strijbos PJ. Regulation of calcitonin gene-related peptide release from rat trigeminal nucleus caudalis slices in vitro. Neurosci Lett. 2004;366:241-244.

46. Lance JW. The pathophysiology of migraine. Ann Acad Med Singapore. 1985;14:4-11.

47. Dahlöf CG. Sumatriptan: Pharmacological basis and clinical results. Curr Med Res Opin. 2001;17(Suppl. 1):s35-s45.

48. Goadsby PJ. Recent advances in understanding migraine mechanisms, molecules and therapeutics. Trends Mol Med. 2007;13:39-44.

49. Moskowitz MA, Cutrer FM. Sumatriptan: A receptor-targeted treatment for migraine. Annu Rev Med. 1993;44:145-154.

50. Shields KG, Goadsby PJ. Serotonin receptors modulate trigeminovascular responses in ventroposteromedial nucleus of thalamus: A migraine target? Neurobiol Dis. 2006;23:491-501.

51. Hoyer D. Functional correlates of serotonin $5-\mathrm{HT}_{1}$ recognition sites. J Recept Res. 1988;8:59-81.

52. Leysen JE. Serotonergic binding sites. In: Vanhoutte PM, ed. Serotonin and the Cardiovascular System. New York, NY: Raven Press; 1985:43-62.

53. Leroy F, Asseman P, Pruvost P, Adnet P, Lacroix D, Thery C. Dihydroergotamine-erythromycin-induced ergotism. Ann Intern Med. 1988;109:249 Abstract.

54. Christians U, Schmidt G, Bader A, et al. Identification of drugs inhibiting the in vitro metabolism of tacrolimus by human liver microsomes. Br J Clin Pharmacol. 1996;41:187-190.

55. Aurora SK, Silberstein SD, Kori SH, et al. MAP0004, orally inhaled DHE: A randomized, controlled study in the acute treatment of migraine. Headache. 2011;51:507-517.
56. Sanders SW, Haering N, Mosberg H, Jaeger H. Pharmacokinetics of ergotamine in healthy volunteers following oral and rectal dosing. Eur J Clin Pharmacol. 1986;30:331-334.

57. Ibraheem JJ, Paalzow L, Tfelt-Hansen P. Low bioavailability of ergotamine tartrate after oral and rectal administration in migraine sufferers. Br J Clin Pharmacol. 1983;16:695-699.

58. Perrin VL. Clinical pharmacokinetics of ergotamine in migraine and cluster headache. Clin Pharmacokinet. 1985;10:334-352.

59. Banhidy F, Acs N, Puho E, Czeizel AE. Ergotamine treatment during pregnancy and a higher rate of low birthweight and preterm birth. Br J Clin Pharmacol. 2007;64:510-516.

60. Connor HE. Sumatriptan - pharmacology. In: Diener HC, ed. Drug Treatment of Migraine and Other Frequent Headaches. Basel: Karger Press; 2000:83-92.

61. Kallen B, Lygner PE. Delivery outcome in women who used drugs for migraine during pregnancy with special reference to sumatriptan. Headache. 2001;41(4):351-356.

62. Gomez-Mancilla B, Cutler NR, Leibowitz MT, et al. Safety and efficacy of PNU-142633, a selective 5-HT $\mathrm{HD}_{1 \mathrm{D}}$ agonist, in patients with acute migraine. Cephalalgia. 2001;21:727-732.

63. Ferrari MD, Farkkila M, Reuter U, et al. Acute treatment of migraine with the selective $5-\mathrm{HT}_{1 \mathrm{~F}}$ receptor agonist lasmiditan - a randomised proof-of-concept trial. Cephalalgia. 2010;30:11701178.

64. Sheftell FD, Dahlöf CG, Brandes JL, Agosti R, Jones MW, Barrett PS. Two replicate randomized, double-blind, placebo-controlled trials of the time to onset of pain relief in the acute treatment of migraine with a fast-disintegrating/rapid-release formulation of sumatriptan tablets. Clin Ther. 2005;27:407-417.

65. Kallen B, Nilsson E, Otterblad Olausson P. Delivery outcome after maternal use of drugs for migraine Drug Saf. 2011;34(8):691-703.

66. Dodick D, Lipton RB, Martin V, et al. Consensus statement: Cardiovascular safety profile of triptans (5-HT agonists) in the acute treatment of migraine. Headache. 2004; 44:414-425.

67. Valentgas P, Cole A, Mo J, et al. Triptan use is not associated with increased risk of severe vascular events in migraine patients. Eur J Neurol. 2002;(Suppl 2):45.

68. Hall GC, Brown MM, Mo J, et al. Migraine, triptan treatment and the risk of cardiovascular disease, stroke and mortality. Eur J Neurol. 2002;9(Suppl. 2):150.

69. Cassina M, Di Gianantonio E, Toldo I, Battistella PA, Clementi M. Migraine therapy during pregnancy and lactation. Expert Opin Drug Saf. 2010;9:937-948.

70. Humphrey PPA. 5-Hydroxytryptamine and the pathophysiology of migraine. J Neurol. 1991;238(Suppl. 1):S38-S44. 